\title{
Editorial:
}

\section{El aprendizaje como pretexto y el aula como contexto de la innovación en Educación Superior}

\author{
Dino Salinas Fernández \\ Universitat de València \\ Didàctica i Organització Escolar \\ Bernardino.Salinas@uv.es \\ Noelia Ibarra-Rius \\ Universitat de València \\ Didàctica de la Llengua i la Literatura \\ Noelia.Ibarra@uv.es
}

Entre las diferentes aproximaciones, enfoques y perspectivas, planteadas sobre todo en los últimos años, en los que se define o reconoce el concepto de "innovación" asociado al de "enseñanza", en este monográfico se abordan problemas relativos a la enseñanza desde la identificación de la innovación con “buenas prácticas", esto es, aquel tipo de práctica de enseñanza (ya sea en su fase de diseño o desarrollo o evaluación) que hace posible el aprendizaje que pretendemos, optimizando las condiciones en las que se desarrolla. Por este motivo, los trabajos que componen el presente monográfico atienden tanto a la descripción de las prácticas como a la del propio contexto institucional que hizo factible su desarrollo. A través de esta breve selección de contribuciones se pretende ofrecer una muestra significativa de la innovación en diferentes universidades $y$ frentes, tanto en torno a la implementación de metodologías activas, como en el ámbito de la evaluación o desde la integración de las tecnologías en la docencia universitaria desde sus diferentes potencialidades.

Así, en "Aprendizaje en entornos laborales y evaluación auténtica", Fortea, Sánchez-Tarazaga y Zorrilla presentan una experiencia de Work Based Learning implementada en el Grado de Maestro de Educación Infantil de la Universitat Jaume I a través de los proyectos de innovación de la UJ 3240/16 y 3241/16 y del proyecto de investigación "Relaciones universidad empresa para la docencia. Motivaciones, impacto y beneficios" (UJIB2016-4).

Por su parte, Gómez Trigueros en "Los proyectos de innovación como recurso formativo en el Máster del
Profesorado" desvela la percepción del alumnado del Máster de Profesorado de la Universidad de Alicante respecto a las propuestas de innovación docente y su integración en las aulas.

Romero, Heredia y Ordóñez con su artículo "Las TIC como elemento de cohesión en el desarrollo de la oralidad mediante el ABP" muestran cómo las TIC pueden contribuir al desarrollo de la competencia comunicativa oral del alumnado desde la metodología del aprendizaje basado en proyectos.

Una experiencia de transferencia del conocimiento desde las Humanidades y las Ciencias de la Educación realizada en la Noche Europea de los Investigadores presentan Campos, Quiles y Martos en "Poetas a pie de calle: espacios para la transferencia en la noche de los investigadores", centrada en la experimentación y producción del lenguaje poético.

Por último, Ibarra-Rius y Ballester y Roca, en "De literatura, cine, publicidad e internet: relatos digitales y book tráilers en la formación de docentes", abordan la relación entre tecnologías de la información y la comunicación y educación lectora y literaria a través de los relatos digitales. Así, estudian el book tráiler como herramienta de gran potencial en la formación de docentes, puesto que permite la adquisición y desarrollo de competencias como la comunicativa, lectora, literaria, artística, social o ciudadana, potencia la creatividad y autonomía del alumnado y fomenta la alfabetización multimodal.

Cita recomendada de este artículo

Salinas Fernadez, Dino; Ibarra Rius, Noelia. (2017)."El aprendizaje como pretexto y el aula como contexto de la innovación en Educación Superior." @tic. revista d'innovació educativa. (nº 19). URL. Fecha de consulta, dd/mm/aaaa. 